\title{
PHARMACEUTICAL PROPERTIES OF VENOM TOXINS AND THEIR POTENTIAL IN DRUG DISCOVERY
}

\section{Jeroen Kool}

Division of BioAnalytical Chemistry, Department of Chemistry and Pharmaceutical Sciences, Faculty of Sciences, VU University Amsterdam, Amsterdam, Netherland

Submitted: $13-12-2015$

Revised: 17-01-2016

Accepted: 29-01-2016

*Corresponding author Jeroen Kool

Email:

j.kool@vu.nl

\begin{abstract}
Traditional pipelines feeding drugs coming to the market are declining. This is one of the reasons why nowadays the previously abandoned natural extract drug discovery programs are slowly coming back. In this scenario, small molecular metabolites from plants and single cell marine or soil organisms are gaining interest in pharmaceutical research again. Animal venoms are another source for finding new biopharmaceutical lead molecules and research interest in discovering bioactive molecules from venoms is rising. Venoms comprise often highly selective and potent bioactive peptides and small proteins for receptors and enzymes that are valid drug targets. This work discusses drug discovery research on bioactive compounds in venoms and gives older and more recent examples of bioactive compounds found in venoms from different animals. Common pharmaceutical targets that different classes of venom toxins interact with and information on developmental stages of several medicinal venom peptides are also discussed.
\end{abstract}

Key words: venom, toxin, drug discovery, peptide, pharmaceutical activity

\section{INTRODUCTION}

Bioactive peptides are widespread in prokaryotic and eukaryotic organisms. In particular, animal venoms have been the origin of several peptide based drugs (Koh and Kini, 2012). Venom drug discovery programs have delivered drugs such as Captopril, Prialt, Integrilin and Byetta, and many candidates are now progressing in clinical trials. Furthermore, peptides derived from venoms are valid pharmacological tools to study diseases (McCleary and Kini, 2013). For example, a study on the snake toxin $\alpha$-bungarotoxin led to the isolation of the nicotinic acetylcholine receptor (nAChR) and a new understanding of the disease myasthenia gravis (Kini and Doley, 2010). Captopril is an inhibitor of the angiotensin converting enzyme (ACE), used to treat high blood pressure (Laing and Moura-daSilva, 2005), which is based on compounds discovered in the venom of the Brazilian snake Bothrops jararaca. Other venom-derived bioactives include the highly potent analgesic hannalgesin ( $\mathrm{Pu}$ et al., 1995) from the venom of the King cobra, and the antithrombotic drug Aggrastat from the venom of the saw-scaled viper. Venoms also contain potent antimicrobial peptides and there has been an increasing stream of publications and patent applications relating to antimicrobial compounds from venoms. Examples are the peptide vgf-1 from venom of the Chinese cobra Naja atra, which is active against multidrug resistant Mycobacterium tuberculosis (Xie et al., 2003), and the peptide microporin from the venom of the scorpion Isometrus maculates that is highly effective against multiple antibiotic resistant bacteria (Zhao et al., 2009). Other examples include opistoporins from scorpion venom (Moerman et al., 2002), the cupiennins, anoplin, parabutoporin (Remijsen et al., 2010), vejovine, hadririne, pandinin and so on. The number and diversity of bioactive peptides in venoms, and the many thousands of animal species that produce them (including various species of snake, scorpion, spider, bee, wasp and cone snail) means that venoms constitute huge libraries of potentially new drugs and useful research tools.

\section{VENOM TOXINS AND THEIR PHARMACEUTICAL POTENTIAL}

Venomous animals use venoms, which are complex mixtures consisting for the major part of peptides and enzymes, for prey acquisition, digestion and/or defense against a 
predator. From a historical point of view, venoms from snakes for example have been used for arthritis and gastrointestinal problems as well as conditions such as pain and rheumatism to polio. Other examples comprise venoms from spiders for treatment of for example asthma and cancer. Besides snakes, many other organisms produce various forms of toxins for defensive and/or offensive situations. These organisms include jellyfish, scorpions, centipedes, anemones, and some venomous fish species (Lewis and Garcia, 2003). These venom cocktails provide a rich source of bioactive peptides with many diverse potential therapeutic effects. From these, chemotherapeutic, anticoagulant, antidiabetic, thrombolytic, immunosuppressive, anticancer, antihypertensive, antibacterial, antiarrhythmic, and analgesic compounds can be named (Lew is and Garcia, 2003; Xu et al., 2006; Khunsap et al., 2011; Koh and Kini, 2012). A review from 2014 thoroughly discusses toxins from venoms in drug discovery and development pipelines (Harvey, 2014).

The composition of venom varies across species. Venomous animals that immobilize or kill prey by venom injection followed by venom mediated digestion, contain neurotoxins and/or highly active digestive enzymes. The toxins in snake venoms among others are toxins that target neurotransmitters and ion channels, and toxins targeting the muscular, cardiovascular and immune system (Koh et al., 2006). Bees, wasps and ants use their venom for defense when they are threatened, inducing inflammatory, immunological, pain inducing, headache, and/or swelling as responses after injection. (King and Spangfort, 2000). Besides venoms, some organisms (mostly parasites) try to avoid attention of their host and as such use their venom (more often called saliva) to locally prevent immune responses, and use local anesthetics to prevent getting their presence noticed. Additionally, anticoagulants are injected to prevent coagulation of host blood (Motoyashiki et al., 2003). A comprehensive review from 2014 on toxins, and their analogs, derived from venoms in drug discovery is thoroughly described by Harvey (Harvey, 2014). Many toxin derived compounds in the have entered clinical trials (King, 2011). But the same as in traditional small molecule drug development, also many of them fail reaching the market with as main causes lack of efficacy, toxicity effects, or economic reasons.

Snake venoms are continuously being explored for new peptides and proteins with medicinal properties for a wide range of syndromes and diseases ( $\mathrm{Pu}$ et al., 1995; King, 2011; Diochot et al., 2012; Earl et al., 2012; Koh and Kini, 2012; Vink et al., 2012). One source of venom toxins relevant to both medicine and as pharmacological tools are cone snail venoms (Lewis and Garcia, 2003; Twede et al., 2009, Essack et al., 2012; Vetter and Lewis, 2012). The biggest success was the market approval of Prialt (Ziconotide) for treatment of patients with severe chronical pain. Ziconotide is a peptide drug initially discovered in Conus magus which actions by blocking the spinal cord resided N-type calcium ion channel Cav2.2 (Pope and Deer, 2013). Other conopeptides have been discovered that target sodium ion channels and several receptors (Vetter and Lewis, 2012). When focusing on pharmacological tools, a-bungarotoxins and conotoxins are important compounds in studying subtype selectivity between nicotinic acetylcholine receptors, by selectively blocking them (Lewis et al., 2012). The pharmacological sites of five of the voltage-gated sodium channels for example were defined by venom toxins (Klint et al., 2012). Sea anemones are other marine species with venom toxins that have potential medicinal properties. For example the synthetic peptide derived from the sea anemone Stichodactyla helianthus. This peptides blocks the potassium ion channel Kv1.3 very selectively and as such has potential medicinal effects in autoimmune diseases and/or MS (Beeton et al., 2011; Chi et al., 2012).

Saliva from parasitic species is per definition not a real venom, but it is a biological matrix with high potential for finding novel bioactive compounds for drug discovery pipelines. In saliva from parasites, compounds with anti-coagulation properties are found which for example aids in treatment of cardiovascular diseases (Stibraniova et al., 2013). Arthropods have anti-coagulating (such as antiplatelet proteins), anti-inflammatory, and vasodilating proteins in their saliva. This allows them to feed from the host for longer periods of time without getting noticed by the host, and 
without blood clotting occurring around the area of feeding (which allows detachment from the host after feeding). These compounds possess very interesting properties from a biopharmaceutical point of view. An added advantage of lead compounds developed from salivary proteins is that they are often antiimmunogenic and antigenic. This reduces probability of immunogenic side effects (Schwalie and Schultz, 2009, Stibraniova, Lahova et al., 2013). Other effects known to be exerted by compounds in saliva from certain ticks and mosquitos are vasodilation, migration of leukocytes, platelet aggregation, coagulation (Mizurini et al., 2013), angiogenesis, and complement activation. One specific class of salivary proteins are the evasins from tick saliva, and aegyptin from moquito saliva (Calvo et al., 2007; Deruaz et al., 2008; Deruaz et al., 2013; Mizurini et al., 2013). Evasins are chemokine-binding proteins. Evasin-1 binds to CCL3, CCL4 and CCL14, evasin-3 binds to CXCL8 and CXCL1, and evasin-4 binds to CCL5 and CCL11 (Deruaz et al., 2008), while other proteins have also been found with chemokine modulating activity (Hajnicka et al., 2001). Examples of potential medical uses involving evasins are evasin- 1 for treatment of idiopathic pulmonary fibrosis (Russo et al., 2011) and evasin-4 for treatment of postinfarction myocardial survival (Braunersreuther, Montecucco et al., 2013). Aegyptin, found in saliva from a mosquito, is a collagen binding protein that inhibits the aggregation and adhesion of platelets (Calvo et al., 2007, Mizurini et al., 2013).

\section{PHARMACEUTICAL TARGETS OF VENOM TOXINS Antiplatelet agents}

Targets of anti-platelet compounds in some venoms include thrombin, ADP receptors, integrins and metalloproteinases. Disintegrins from several snake venoms function as agonist (thereby preventing the binding of fibrinogen) (Bledzka et al., 2013). Integrin $\alpha_{2} \beta_{1}$ for example is responsible for platelet adhesion and agonistic lectin-like proteins have been found in venoms from snakes (Arlinghaus and Eble, 2012). Some three-finger toxins have anti-platelet activity (Chanda et al., 2013), while venom derived metalloproteinases disrupt platelet adhesion and aggregation (Santos-Martinez et al., 2008).

\section{Pro- and anti-coagulant agents}

Many snake venoms have thrombin like enzymes which show similarity to thrombin, an important enzyme in the coagulation cascade (Valeriano-Zapana et al., 2012), while prothrombin activators are also found in snake venoms with comparable functions as Factor $\mathrm{X}$ (Tans and Rosing, 2001; Joseph and Kini, 2004, Segers et al., 2006). Thrombin inhibitors and activators have also been identified in snake venoms, and these inhibitors can act as potential anti-coagulation agents (Matsui et al., 2000). After the bleeding of a wound stops the clot must dissolve again, which is facilitated by fibrinolysis for which the serine proteinase plasmin is responsible. In this process, fibrin is converted into soluble products. Dissolving clots has potential therapeutic applications and as such fibrin(ogen)olytic enzymes (e.g. serine proteinases and metalloproteinases) from snake venoms are interesting to study from a pharmaceutical point of view (Lu et al., 2005). For hypertension, the angiotensin converting enzyme (ACE) is a major target (treatment of hypertension and heart failure), and is of interest in cardiovascular diseases and diabetic nephropathy (Kearney et al., 2005). Next to many ACE inhibiting compounds identified in plants (Somanadhan et al., 1999), venoms comprise another source of candidate peptides with ACE inhibiting potential. Captopril in this regard is the best known example of an ACE inhibiting drug derived from snake venom. Many proteins found in tick and mosquito saliva targeting coagulation, such as thrombin and factor Xa inhibitors (Lai et al., 2004), and platelet aggregation inhibitors (Sun et al., 2006), are interesting study for their potential as anticoagulation agents. Yet other targets of tick salivary proteins are T-cells, B-cells, dendritic cells and complement factors C3 and C5 in a immunosuppressive manner (Hajnicka et al., 2011; Wikel 2013).

\section{Antibacterials, antifungals and antivirals \\ Certain wasps procreate by injecting} their offspring into parasitized species and to prevent infection, defensin-like antimicrobial 
peptides are present in the venom of these wasps (Ye et al., 2010). Other antibacterial peptides found in venoms comprise the peptides pilosulin 3 and 4 found in a jumper ant (Inagaki et al., 2004), although these peptides also possess allergenic properties. Venom and/or saliva from many honeybees have antifungal activity. Also, the larvae of some bees have antibacterial and antifungal secretions to protect their bee hives (Ergin et al., 2006). Melittin for example, a protein found in honeybee venom, has antiviral properties against different viruses such as HIV-1 and the herpes simplex virus (Wachinger et al., 1998). As this compound is also hemolytic and an allergen, the interest in its medicinal properties are limited, but it does stay a valid starting point for development of more suitable derivatives.

\section{Anticancer agents}

Bee venom has several desirable pharmacological effects such as antiinflammatory, antimutagenic, radioprotective, and anticancer effects. For the reported anticancer effects, induction of apoptosis and necrosis, and growth inhibition can be named (Jang et al., 2003; Hu, Chen et al. 2006; Han et al.; 2007). The venom derived phospholipase A2 crotoxin interacts with the epidermal grow th factor receptor and showed activity in a phase I clinical trial, next to showing activity in several cell lines. Apamin, which is yet another bee venom toxin, can activate p53 in certain tumors which can lead to a reduction in tumor growth (Orsolic, 2012). Integrins are suggested as drug targets for cancer cell adhesion, migration and angiogenesis inhibition. In the example of contortrostatin, a disintegrin from snake venom, it proved effective in inhibiting tumor growth, angiogenesis and metastasis in ovarian and breast cancer. Additionally, other disintegrins targeting integrin $\alpha_{1} \beta_{1}$ have demonstrated reduction of angiogenesis and metastasis (Koh and Kini, 2012).

\section{Ion channel targets}

Major targets of venom toxins are ion channels, which are also important pharmaceutical targets for among others neurodegenerative and pain related diseases. Animal toxins targeting ion channels are mainly short to medium sized peptides found in a large variety of species. Venom toxins are known to very specifically and often very potently (in different modes; e.g. agonistic or antagonistic manner) target different ion channels such as voltage-gated potassium, sodium, and calcium channels, and also ligand-gated nicotinic acetylcholine receptors (Dutertre and Lewis, 2010). In venom cocktails they mainly act as neurotoxins, but individually many are highly selective and potent and as such are considered as biopharmaceutical candidates and/or pharmacological tools (Joseph and Kini, 2004; Barber et al., 2013; Brady et al., 2013, Min et al., 2013; Kularatne and Senanayake, 2014; Tsetlin, 2015). The neurotoxin alpha-cobratoxin for example might be interesting in relation to multiple sclerosis (Reid, 2007). Another example, Prialt, was developed from a conotoxin and is a potent drug against severe chronical pain.

\section{CONCLUSION}

Venoms are a promising source for finding novel bioactives targeting several enzymes and receptors involved in disease. Drug discovery approaches focussing on venom derived bioactives demand a different workflow than traditional small molecule drug discovery and development pipelines. Venom derived biopharmaceutical lead compounds are discovered and developed in a way that combines both traditional small molecular drug discovery, biopharmaceutical research, and traditional natural extract drug discovery programs (i.e. from plants). For venoms, the discovery and identification aspect is in part similar to traditional natural extract drug discovery programs. With venom derived drug discovery, however, straightforward medicinal peptide synthetic approaches can be used to optimize leads pharmacologically and toxicologically, which is often more complicated in case of small molecules identified from plant extracts. Furthermore, bioactive peptides and proteins can be overexpressed and produced in large fermentors that are also applied standard biopharmaceutical development processes. In case of venom peptides, genetic modification allows structural modification of the peptides for pharmacological optimization purposes. By rationally modifying amino acids of these 
bioactive peptides, their pharmacological properties can be altered and optimized. Venom based drug discovery processes and academic research is not mainstream yet, but it is expected that it will slowly gain more interest and volume considering the many different highly potent and selective compounds that are yet to be discovered from venoms. As this field of research is strongly technology driven, advancements in analytics, biotechnology, biology, biochemistry, and peptide synthesis all are expected to contribute to better and more efficient drug discovery from the exiting natural recourses that venoms are.

\section{REFE RE NCES}

Arlinghaus FT., Eble JA. 2012. "C-type lectinlike proteins from snake venoms." Toxicon 60(4): 512-519.

Barber CM., Isbister GK. and Hodgson WC. 2013. "Alpha neurotoxins." Toxicon 66: 47-58.

Beeton C., Pennington MW and Norton RS. 2011. "Analogs of the sea anemone potassium channel blocker ShK for the treatment of autoimmune diseases." Inflamm Allergy Drug Targets 10(5): 313321.

Bledzka K., Smyth SS. and Plow EF. 2013. "Integrin alphaIIbbeta3: from discovery to efficacious therapeutic target." Circ Res 112(8): 1189-1200.

Brady RM., Baell JB. and Norton RS. 2013. "Strategies for the development of conotoxins as new therapeutic leads." Mar Drugs 11(7): 2293-2313.

Braunersreuther V., Montecucco F., Pelli G., Galan K., Proudfoot AE. et al., 2013. "Treatment with the CC chemokinebinding protein Evasin-4 improves postinfarction myocardial injury and survival in mice." Thromb Haemost 110(4): 807825.

Calvo E., Tokumasu F., Marinotti O., Villeval JL., et al. 2007). "Aegyptin, a novel mosquito salivary gland protein, specifically binds to collagen and prevents its interaction with platelet glycoprotein VI, integrin alpha2beta1, and von Willebrand factor." J.Biol.Chem. 282(37): 26928-26938.
Chanda C., Sarkar A., Sistla S. and Chakrabarty D. 2013. "Anti-platelet activity of a three-finger toxin (3FTx) from Indian monocled cobra (Naja kaouthia) venom." Biochem Biophys Res Commun 441(3): 550-554.

Chi V., Pennington MW., Norton RS., Tarcha EJ., Londono LM., Sims-Fahey B., Upadhyay SK. et al. 2012. "Development of a sea anemone toxin as an immunomodulator for therapy of autoimmune diseases." Toxicon 59(4): 529-546.

Deruaz M., Bonvin P., Severin IC., Johnson Z., Krohn S. et al. 2013. "Evasin-4, a tickderived chemokine-binding protein with broad selectivity can be modified for use in preclinical disease models." FEBS $J$ 280(19): 4876-4887.

Deruaz M., Frauenschuh A., Alessandri AL., Dias JM., Coelho FM. et al. 2008. "Ticks produce highly selective chemokine binding proteins with antiinflammatory activity." J Exp Med 205(9): 2019-2031.

Diochot S., Baron A., Salinas M., Douguet D., Scarzello S. et al. 2012. "Black mamba venom peptides target acid-sensing ion channels to abolish pain." Nature 490 (7421): 552-555.

Dutertre S. and Lewis RJ. 2010. "Use of venom peptides to probe ion channel structure and function." J Biol Chem 285(18): 13315-13320.

Earl ST., Masci PP., de Jersey J., Lavin MF. and Dixon J. 2012. "Drug development from Australian elapid snake venoms and the Venomics pipeline of candidates for haemostasis: Textilinin-1 (Q8008), Haempatch (Q8009) and CoVase (V0801)." Toxicon 59(4): 456-463.

Ergin E., Uckan F., Rivers DB. and Sak O. 2006. "In vivo and in vitro activity of venom from the endoparasitic wasp Pimpla turionellae (L.) (Hymenoptera: Ichneumonidae)." Arch Insect Biochem Physiol 61(2): 87-97.

Essack M., Bajic VB. and Archer JA. 2012. "Conotoxins that confer therapeutic possibilities." Mar Drugs 10(6): 12441265.

Hajnicka V., Kocakova P., Slavikova M., Slovak M., Gasperik J. et al. 2001. "Antiinterleukin-8 activity of tick salivary 
gland extracts." Parasite Immunol 23(9): 483-489.

Hajnicka V., Vancova-Stibraniova I., Slovak M., Kocakova P. and. Nuttall PA, 2011. "Ixodid tick salivary gland products target host wound healing growth factors." Int J Parasitol 41(2): 213-223.

Han S., Lee K., YeoJ., Kweon H., Woo S., Lee M., Baek H., Kim S. and Park K. 2007. "Effect of honey bee venom on microglial cells nitric oxide and tumor necrosis factor-alpha production stimulated by LPS." J Ethnopharmacol 111(1): 176-181.

Harvey AL. 2014. "Toxins and drug discovery." Toxicon 92: 193-200.

Hu H., Chen D., Li Y. and Zhang X. 2006. "Effect of polypeptides in bee venom on growth inhibition and apoptosis induction of the human hepatoma cell line SMMC-7721 in-vitro and Balb/c nude mice in-vivo." J Pharm Pharmacol 58(1): 83-89.

Inagaki H., Akagi M., Imai HT., Taylor RW. and Kubo T. 2004). "Molecular cloning and biological characterization of novel antimicrobial peptides, pilosulin 3 and pilosulin 4, from a species of the Australian ant genus Myrmecia." Arch Biochem Biophys 428(2): 170-178.

Jang MH., Shin MC., Lim S., Han SM., Park HJ., Shin I., Lee JS., Kim KA., Kim EH. and Kim CJ. 2003. "Bee venom induces apoptosis and inhibits expression of cyclooxygenase- 2 mRNA in human lung cancer cell line NCI-H1299." J Pharmacol Sci 91(2): 95-104.

Joseph JS. and Kini RM. 2004. "Snake venom prothrombin activators similar to blood coagulation factor Xa." Curr Drug Targets Cardiovasc Haematol Disord 4(4): 397-416.

Kearney PM., Whelton M., Reynolds K., Muntner P., Whelton PK. and $\mathrm{He} \mathrm{J}$. 2005. "Global burden of hypertension: analysis of worldwide data." Lancet 365(9455): 217-223.

Khunsap S., Pakmanee N., Khow O., L. Chanhome, V. Sitprija, M. Suntravat, S. E. Lucena, J. C. Perez and E. E. Sanchez (2011). "Purification of a phospholipase $\mathrm{A}(2)$ from Daboia russelii siamensis venom with anticancer effects." $J$ Venom Res 2: 42-51.

King GF. 2011. "Venoms as a platform for human drugs: translating toxins into therapeutics." Expert Opin Biol Ther 11(11): 1469-1484.

King, T. P. and M. D. Spangfort (2000). "Structure and biology of stinging insect venom allergens." Int Arch Allergy Immunol 123(2): 99-106.

Kini RM. and Doley R. 2010. "Structure, function and evolution of three-finger toxins: mini proteins with multiple targets." Toxicon 56(6): 855-867.

Klint JK., Senff S., Rupasinghe DB., Er SY., Herzig V., Nicholson GM. and King GF. 2012. "Spider-venom peptides that target voltage-gated sodium channels: pharmacological tools and potential therapeutic leads." Toxicon 60(4): 478491.

Koh CY. and Kini RM. 2012. "From snake venom toxins to therapeutics-cardiovascular examples." Toxicon 59(4): 497-506.

Koh DC., Armugam A. and Jeyaseelan K. 2006. "Snake venom components and their applications in biomedicine." Cell $\mathrm{Mol}$ Life Sci 63(24): 3030-3041.

Kularatne, S. A. and N. Senanayake (2014). "Venomous snake bites, scorpions, and spiders." Handb Clin Neurol 120: 9871001.

Lai R., Takeuchi H., Jonczy J., Rees HH. and Turner PC. 2004. "A thrombin inhibitor from the ixodid tick, Amblyomma hebraeum." Gene 342(2): 243-249.

Laing GD. and Moura-da-Silva AM. 2005. "Jararhagin and its multiple effects on hemostasis." Toxicon 45(8): 987-996.

Lewis RJ., Dutertre S., Vetter I. and Christie MJ. 2012. "Conus venom peptide pharmacology." Pharmacol Rev 64(2): 259298.

Lewis RJ. and Garcia ML. 2003. "Therapeutic potential of venom peptides." Nat Rev Drug Discov 2(10): 790-802.

Lu Q., Clemetson JM. and Clemetson KJ. 2005. "Snake venoms and hemostasis." J Thromb Haemost 3(8): 1791-1799.

Matsui T., Fujimura Y. and Titani K. 2000. "Snake venom proteases affecting 
hemostasis and thrombosis." Biochim Biophys Acta 1477(1-2): 146-156.

McCleary RJ. and Kini RM. 2013. "Nonenzymatic proteins from snake venoms: a gold mine of pharmacological tools and drug leads." Toxicon 62: 56-74.

Min JW., Liu WH., He XH. and B. W. Peng (2013). "Different types of toxins targeting TRPV1 in pain." Toxicon 71: 6675.

Mizurini DM., Francischetti IM. and Monteiro RQ. 2013. "Aegyptin inhibits collageninduced coagulation activation in vitro and thromboembolism in vivo." Biochem Biophys Res Commun 436(2): 235-239.

Moerman L., Bosteels S., Noppe W., Willems J., Clynen E., Schoofs L., Thevissen K., Tytgat J., Van Eldere J., Van Der Walt J. and Verdonck F. 2002. "Antibacterial and antifungal properties of alphahelical, cationic peptides in the venom of scorpions from southern Africa." Eur.J.Biochem. FEBS 269(19): 4799-4810.

Motoyashiki T., Tu AT., Azimov DA. and Ibragim K. 2003. "Isolation of anticoagulant from the venom of tick, Boophilus calcaratus, from Uzbekistan." Thromb Res 110(4): 235-241.

Orsolic N. 2012. "Bee venom in cancer therapy." Cancer Metastasis Rev 31(1-2): 173-194.

Pope JE. and Deer TR. 2013. "Ziconotide: a clinical update and pharmacologic review." Expert Opin Pharmacother 14(7): 957-966.

Pu, X. C., P. T. Wong and P. Gopalakrishnakone (1995). "A novel analgesic toxin (hannalgesin) from the venom of king cobra (Ophiophagus hannah)." Toxicon 33(11): 1425-1431.

Reid PF. (2007). "Alpha-cobratoxin as a possible therapy for multiple sclerosis: a review of the literature leading to its development for this application." Crit Rev Immunol 27(4): 291-302.

Remijsen Q., Verdonck F. and Willems J. 2010. "Parabutoporin, a cationic amphipathic peptide from scorpion venom: much more than an antibiotic." Toxicon : official journal of the International Society on Toxinology 55(2-3): 180-185.
Russo RC., Alessandri AL., Garcia CC., Cordeiro BF., Pinho V., Cassali GD., Proudfoot AE. and Teixeira MM. 2011. "Therapeutic effects of evasin-1, a chemokine binding protein, in bleomycin-induced pulmonary fibrosis." Am J Respir Cell Mol Biol 45(1): 72-80.

Santos-Martinez MJ., Medina C., Jurasz P. and Radomski MW. 2008. "Role of metalloproteinases in platelet function." Thromb Res 121(4): 535-542.

Schwalie PC. and Schultz J. 2009. "Positive selection in tick saliva proteins of the Salp15 family." J Mol Evol 68(2): 186-191.

Segers K., Rosing J. and Nicolaes GA. 2006. "Structural models of the snake venom factor $\mathrm{V}$ activators from Daboia russelli and Daboia lebetina." Proteins 64(4): 968984.

Somanadhan B., Varughese G., Palpu P., Sreedharan R., Gudiksen L., Smitt UW. and Nyman U. 1999). "An ethnopharmacological survey for potential angiotensin converting enzyme inhibitors from Indian medicinal plants." J Ethnopharmacol 65(2): 103-112.

Stibraniova I., Lahova M. and Bartikova P. 2013. "Immunomodulators in tick saliva and their benefits." Acta Virol 57(2): 200216.

Sun D., McNicol A., James AA. and Peng Z. 2006. "Expression of functional recombinant mosquito salivary apyrase: a potential therapeutic platelet aggregation inhibitor." Platelets 17(3): 178-184.

Tans G. and Rosing J. 2001. "Snake venom activators of factor X: an overview." Haemostasis 31(3-6): 225-233.

Tsetlin VI. 2015. "Three-finger snake neurotoxins and Ly6 proteins targeting nicotinic acetylcholine receptors: pharmacological tools and endogenous modulators." Trends Pharmacol Sci 36(2): 109-123.

Twede VD., Miljanich G., Olivera BM. and Bulaj G. 2009. "Neuroprotective and cardioprotective conopeptides: an emerging class of drug leads." Curr Opin Drug Discov Devel 12(2): 231-239.

Valeriano-Zapana JA., Segovia-Cruz FS., RojasHualpa JM., Martins-de-Souza D., Ponce-Soto LA. and Marangoni S. 2012. 
"Functional and structural characterization of a new serine protease with thrombin-like activity TLBan from Bothrops andianus (Andean Lancehead) snake venom." Toxicon 59(2): 231-240.

Vetter I. and Lewis RJ. 2012. "Therapeutic potential of cone snail venom peptides (conopeptides)." Curr Top Med Chem 12(14): 1546-1552.

Vink S., Jin AH., Poth KJ., Head GA. and Alewood PF. 2012. "Natriuretic peptide drug leads from snake venom." Toxicon 59(4): 434-445.

Wachinger M., Kleinschmidt A, Winder D., von Pechmann N., Ludvigsen A., Neumann M., Holle R., Salmons B., Erfle V. and Brack-Werner R. 1998. "Antimicrobial peptides melittin and cecropin inhibit replication of human immunodeficiency virus 1 by suppressing viral gene expression." J Gen Virol 79 ( Pt 4): 731-740.

Wikel S. 2013. "Ticks and tick-borne pathogens at the cutaneous interface: host defenses, tick countermeasures, and a suitable environment for pathogen establishment." Front Microbiol 4: 337.

Xie JP., Yue J., Xiong YL., Wang WY., Yu SQ. and Wang HH. 2003. "In vitro activities of small peptides from snake venom against clinical isolates of drug-resistant Mycobacterium tuberculosis." Int J Antimicrob.Agents 22(2): 172-174.

Xu X., Li J., Lu Q., Yang H., Zhang Y. and Lai R. 2006. "Two families of antimicrobial peptides from wasp (Vespa magnifica) venom." Toxicon 47(2): 249-253.

Ye J., Zhao H., Wang H., Bian J. and Zheng R. 2010. "A defensin antimicrobial peptide from the venoms of Nasonia vitripennis." Toxicon 56(1): 101-106.

Zhao Z., Ma Y., Dai C., Zhao R., Li S., Wu Y., Cao Z. and Li W. 2009. "Imcroporin, a new cationic antimicrobial peptide from the venom of the scorpion Isometrus maculates." Antimicrobial agents and chemotherapy 53(8): 3472-3477. 